\title{
Does Triatoma brasiliensis occupy the same environmental niche space as Triatoma melanica?
}

\author{
Rita de Cássia Moreira de Souza ${ }^{1 * \dagger}$, Gabriel H Campolina-Silva ${ }^{1 \dagger}$, Claudia Mendonça Bezerra ${ }^{2}$, Liléia Diotaiuti ${ }^{1}$ \\ and David E Gorla ${ }^{3}$
}

\begin{abstract}
Background: Triatomines (Hemiptera, Reduviidae) are vectors of Trypanosoma cruzi, the causative agent of Chagas disease, one of the most important vector-borne diseases in Latin America. This study compares the environmental niche spaces of Triatoma brasiliensis and Triatoma melanica using ecological niche modelling and reports findings on DNA barcoding and wing geometric morphometrics as tools for the identification of these species.

Methods: We compared the geographic distribution of the species using generalized linear models fitted to elevation and current data on land surface temperature, vegetation cover and rainfall recorded by earth observation satellites for northeastern Brazil. Additionally, we evaluated nucleotide sequence data from the barcode region of the mitochondrial cytochrome c oxidase subunit I (CO1) and wing geometric morphometrics as taxonomic identification tools for T. brasiliensis and T. melanica.

Results: The ecological niche models show that the environmental spaces currently occupied by T. brasiliensis and T. melanica are similar although not equivalent, and associated with the caatinga ecosystem. The CO1 sequence analyses based on pair wise genetic distance matrix calculated using Kimura 2-Parameter (K2P) evolutionary model, clearly separate the two species, supporting the barcoding gap. Wing size and shape analyses based on seven landmarks of 72 field specimens confirmed consistent differences between T. brasiliensis and T. melanica.

Conclusion: Our results suggest that the separation of the two species should be attributed to a factor that does not include the current environmental conditions. However, as the caatinga is a biome that has existed in the area for at least the last 18,000 years, past conditions might have had an influence in the speciation process. The DNA Barcoding approach may be extended to these members of the subfamily Triatominae.
\end{abstract}

Keywords: Triatominae, Geometric Morphometrics, DNA barcode, Chagas disease, Geographic distribution, Ecological niche modelling

\section{Background}

The epidemiological importance of the Triatominae, a subfamily of blood-sucking bugs, derives from its capacity to transmit Trypanosoma cruzi, the etiological agent of Chagas disease, one of the most important vector borne diseases affecting around 8 million people in Latin America [1]. At present, 148 triatomine species are recognized, whose taxonomic knowledge reflects a balance between the use of traditional approaches and a wide variety of evolutionary interpretations $[2-8]$.

\footnotetext{
*Correspondence: rita@cpqrr.fiocruz.br

${ }^{\dagger}$ Equal contributors

'Laboratório de Triatomíneos e Epidemiologia da Doença de Chagas, Centro de Pesquisas René Rachou, Fundação Oswaldo Cruz, CEP 30.190-002 Belo Horizonte, Minas Gerais, Brazil

Full list of author information is available at the end of the article
}

Triatoma brasiliensis sensu lato Neiva, 1911 is one of the most important species for Chagas disease transmission and the main vector of T. cruzi in semi-arid areas of Northeastern Brazil, colonizing both natural and artificial ecotopes $[9,10]$. This species shows remarkable chromatic variation across its geographic distribution, and indeed, it was concluded that $T$. brasiliensis is a complex of species.

Multidisciplinary studies have indicated that the Triatoma brasiliensis complex is a monophyletic group $[11,12]$, comprising four species, one of which includes two distinct subspecies. The relevant taxa in the group are T. brasiliensis brasiliensis Neiva, 1911; T. brasiliensis macromelasoma Galvão, 1956; Triatoma juazeirensis 
Costa \& Felix, 2007; Triatoma melanica Neiva \& Lent, 1941 and Triatoma sherlocki Papa et al. 2002. Each member of the group can be identified by external morphological characteristics and a taxonomic key was recently published [12].

Correct taxonomic identification of these insects is important because triatomine bugs behave differently in terms of their adaptation to artificial environments. Some species are primarily found in sylvatic ecotopes, where they live associated with small nest-building mammals or birds. Others invade and can even colonize the peridomestic environment and/or the human dwellings, exposing domestic mammals and humans to the infection of T. cruzi [13-17]. Knowledge about the environmental space occupied by the triatomine species is an important factor for the development and/or improvement of vector control and surveillance strategies [18].

Currently, complementary methods to the classical taxonomy have been used in the comparative study of Triatominae species, such as geometric morphometric and molecular techniques. Wing shape is increasingly utilized in species identification and characterization [19] and in distinguishing sibling species [20-22].

Wings are excellent structures for studying morphological variation because the intersections of the wing veins provide many well-defined landmarks suitable for morphometrics, and the metric properties of the wing provide precise quantitative information for the identification of species complexes [23, 24] and within-species variations [25]. In triatomines, the study of morphological variation by geometric morphometrics has been helpful to solve taxonomic problems [20, 26, 27], to analyze the house reinfestation phenomenon [28, 29] and to distinguish cryptic species [23, 30, 31].

Variations that are not expressed phenotypically ascribes importance to molecular studies for the comprehension of systematic issues. In this sense, the DNA sequencing has been widely used for identification, determination of phylogenetic relationships and inferences. The DNA Barcoding method is a system of universal taxonomic identification, fast with free access, based on the variation of a part of the sequence of the mitochondrial gene cytochrome c oxidase subunit I (CO1) [32]. This method remains in constant evaluation and, among other groups, the use of the CO1 sequences has shown promise for species-level identification in insects, including cryptic species of triatomines [33-36] and other insects [37-41].

After the confirmation of the species composition of the $T$. brasiliensis complex, we started exploration about the causes of the speciation process within the complex. Guided by the general question on speciation causes, this study aims at verifying the hypothesis that T. brasiliensis and T. melanica occupy different environmental niche spaces as a consequence of the speciation process within the T. brasiliensis complex. For the first time, we report findings on DNA barcoding as a tool for the identification of these species, and to complement, we also report the analysis of wing geometric morphometrics.

\section{Methods \\ Insects}

The study was based on a dataset that combined localities where sylvatic specimens of $T$. brasiliensis and $T$. melanica were collected in the municipalities of Ceará and Minas Gerais, respectively, by our study group, and localities listed in recent bibliographic records (Table 1) [42-50]. Specimens were collected among rocky crevices by manual capture performed by ourselves, assisted by the personnel of the Chagas Disease Control Programme (PCDCh). Species identification was based on diagnostic characters [12] and supported by geometric morphometric and DNA barcoding.

\section{Geometric morphometrics}

Right hemelytra (forewings) from 36 insects of each species (18 females and 18 males), from the municipalities of Tauá (CE) and Espinosa (MG), were mounted between microscope slides. The wing images were captured using a digital camera (Carl Zeiss ${ }^{\oplus}$ Axiocam MRC 3.0) coupled to a Zeiss ${ }^{\oplus}$ Stemi SV6 stereomicroscope. Seven type I landmarks (venation intersection, according to Bookstein, 1991) were digitized, as shown in Fig. 1. In order to reduce the measurement error, landmark coordinates were recorded three times on each wing and the average of the results was calculated.

Centroid size (CS), an isometric estimator derived from coordinate data, was computed as a measure of overall wing size. It is defined as the square root of the sum of the squared distances between the centre of the configuration of landmarks and each individual landmark [51]. The centroid size values of different species and sexes were compared by multiple linear regression using the "lm function" of $\mathrm{R}$. The presence of atypical points (outliers) was verified and a $95 \%$ confidence interval for the estimated regression coefficients was constructed. In this analysis, males and females were examined separately to check for the presence of sexual dimorphism.

Generalized Procrustes Analysis (GPA) superimposition algorithm [52] was used to produce shape variables. Here, both non-uniform ('Partial Warps') and the uniform component were used as shape variables, which describe respectively the local and global variation as deviations from a consensus shape [53]. In order to explore the wing shape variation among species, a multivariate discriminant analysis was performed on shape variables and the main results were shown by a factorial map of 
Table 1 Triatoma brasiliensis and Triatoma melanica collection sites

\begin{tabular}{|c|c|c|c|}
\hline Espécie & Localities (Estate) & Coordinates & \\
\hline \multirow{40}{*}{ T. brasiliensis } & \multirow{9}{*}{$\begin{array}{l}\text { Cachoeira do } \\
\text { Júlio (CE) }\end{array}$} & -5.7797386568 & -40.2799790369 \\
\hline & & -5.7943959655 & -40.2933588601 \\
\hline & & -5.7957817887 & -40.2964052389 \\
\hline & & -5.7981479146 & -40.29790065 \\
\hline & & -5.7810796276 & -40.2868991416 \\
\hline & & -5.7756609478 & -40.2914290151 \\
\hline & & -5.7745058503 & -40.290306677 \\
\hline & & -5.7707807942 & -40.2898106334 \\
\hline & & -5.7663582906 & -40.2777547391 \\
\hline & \multirow[t]{16}{*}{ Mutuca (CE) } & -5.7639571507 & -40.3154218119 \\
\hline & & -5.7639571507 & -40.3154218119 \\
\hline & & -5.7510605317 & -40.3074732164 \\
\hline & & -5.7529589079 & -40.3078567957 \\
\hline & & -5.7546603659 & -40.3073459943 \\
\hline & & -5.7538574416 & -40.3104142327 \\
\hline & & -5.7571074248 & -40.3129680423 \\
\hline & & -5.7545489571 & -40.3086008597 \\
\hline & & -5.7634536703 & -40.3141293975 \\
\hline & & -5.760313526 & -40.3188447104 \\
\hline & & -5.7593630921 & -40.3152848227 \\
\hline & & -5.7509785672 & -40.3037708967 \\
\hline & & -5.7505637589 & -40.3032372062 \\
\hline & & -5.7540372706 & -40.302983254 \\
\hline & & -5.7556812626 & -40.3038719055 \\
\hline & & -5.7594241925 & -40.3044493114 \\
\hline & \multirow[t]{3}{*}{ Caico (RN) $[42,50]$} & -6.4580555556 & -37.0552 \\
\hline & & -6.4586111111 & -37.1027777778 \\
\hline & & -6.45 & -37.0833333333 \\
\hline & João Costa (PI) [42] & -8.5625 & -42.2615 \\
\hline & \multirow{4}{*}{$\begin{array}{l}\text { Jaguaruana (CE) } \\
{[42-44]}\end{array}$} & -4.83388888899 & -37.4652 \\
\hline & & -4.7908333333 & -37.8211111111 \\
\hline & & -4.7911111111 & -37.8416666667 \\
\hline & & -4.8358333333 & -37.78 \\
\hline & $\begin{array}{l}\text { Independencia } \\
\text { (CE) [46] }\end{array}$ & -5.3833333333 & -40.19 \\
\hline & Tauá (CE) & -6.0030555556 & -40.2927777778 \\
\hline & $\begin{array}{l}\text { Monteiro } \\
\text { (PB) [49] }\end{array}$ & -7.8913888889 & -37.1169444444 \\
\hline & $\begin{array}{l}\text { Mãe d'Água } \\
\text { (PB) [49] }\end{array}$ & -7.2527777778 & -37.4327777778 \\
\hline & $\begin{array}{l}\text { Lagoa Grande } \\
\text { (PE) [49] }\end{array}$ & -8.9852777778 & -40.3055555556 \\
\hline & $\begin{array}{l}\text { Serra Talhada } \\
\text { (PE) [49] }\end{array}$ & -7.9858333333 & -38.2938888889 \\
\hline & & -6.8666666667 & -38.6333333333 \\
\hline
\end{tabular}

Table 1 Triatoma brasiliensis and Triatoma melanica collection sites (Continued)

\begin{tabular}{|c|c|c|}
\hline \multicolumn{3}{|l|}{$\begin{array}{l}\text { São José } \\
\text { (PB) [49] }\end{array}$} \\
\hline $\begin{array}{l}\text { Santa Cruz } \\
\text { (PB) }[49]\end{array}$ & -6.5258333333 & -38.0566666667 \\
\hline $\begin{array}{l}\text { São Francisco } \\
\text { (PB) [49] }\end{array}$ & -6.6147222222 & -38.0894444444 \\
\hline $\begin{array}{l}\text { Jaguaruana } \\
\text { (CE) [45] }\end{array}$ & -4.86666666667 & -37.86666666667 \\
\hline $\begin{array}{l}\text { Morada Nova } \\
\text { (CE) [47] }\end{array}$ & -5.1066666667 & -38.3725 \\
\hline Caicó (RN) [48] & -6.4583333333 & -37.0977777778 \\
\hline \multirow[t]{6}{*}{ Santa Fé (CE) } & -5.79861 & -41.39784 \\
\hline & -5.76942 & -41.38401 \\
\hline & -5.80709 & -41.38547 \\
\hline & -5.807068529 & -41.3656128355 \\
\hline & -5.8066754454 & -41.3636071708 \\
\hline & -5.8066401856 & -41.3632278149 \\
\hline Betânia (CE) & -5.7996606198 & -41.3164524623 \\
\hline \multirow{3}{*}{$\begin{array}{l}\text { Merejo do } \\
\text { Angico (CE) }\end{array}$} & -5.7970432243 & -41.3675663039 \\
\hline & -5.7972957301 & -41.3678649052 \\
\hline & -5.7897151958 & -41.3760729586 \\
\hline \multirow{6}{*}{$\begin{array}{l}\text { São Bento do } \\
\text { Incra (CE) }\end{array}$} & -5.8217903855 & -41.3052064709 \\
\hline & -5.8216638327 & -41.305179086 \\
\hline & -5.82219407 & -41.3027239521 \\
\hline & -5.5448297123 & -41.2859612517 \\
\hline & -5.8244361104 & -41.3031084099 \\
\hline & -5.8244361104 & -41.3031084099 \\
\hline \multirow[t]{9}{*}{ Umburana (CE) } & -5.8067181193 & -41.2836429863 \\
\hline & -5.8065007531 & -41.2837779525 \\
\hline & -5.8038787237 & -41.2834378894 \\
\hline & -5.8041314457 & -41.2836642239 \\
\hline & -5.8040407996 & -41.2837543239 \\
\hline & -5.8011474622 & -41.2754126471 \\
\hline & -5.8010926881 & -41.2756382863 \\
\hline & -5.8009294863 & -41.2758185293 \\
\hline & -5.8009476357 & -41.2757914787 \\
\hline \multirow{9}{*}{$\begin{array}{l}\text { Morada Nova } \\
\text { do Pedro (CE) }\end{array}$} & -5.8183702425 & -41.2940818102 \\
\hline & -5.8185060277 & -41.2940279364 \\
\hline & -5.818089856 & -41.2940901997 \\
\hline & -5.818090084 & -41.2939908626 \\
\hline & -5.8171389269 & -41.290710548 \\
\hline & -5.8166869508 & -41.2906101799 \\
\hline & -5.8150583777 & -41.290886418 \\
\hline & -5.8170585434 & -41.2942142713 \\
\hline & -5.8169040397 & -41.2984763947 \\
\hline
\end{tabular}


Table 1 Triatoma brasiliensis and Triatoma melanica collection sites (Continued)
Table 1 Triatoma brasiliensis and Triatoma melanica collection sites (Continued)

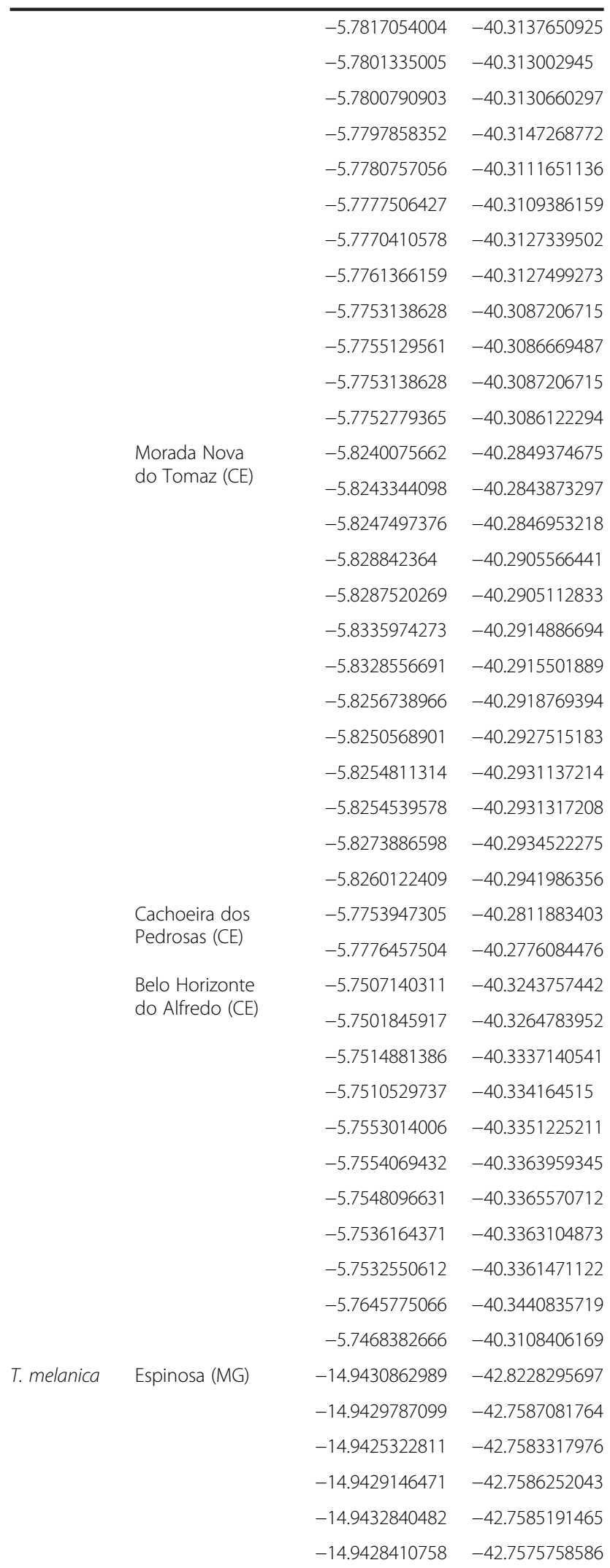


Table 1 Triatoma brasiliensis and Triatoma melanica collection sites (Continued)

\begin{tabular}{lll}
\hline & -14.9261111111 & -42.8191666667 \\
Monte Azul & -15.0649784693 & -42.9291096633 \\
$(\mathrm{MG})$ & -15.0651120404 & -42.9288944895 \\
& -15.0651088061 & -42.9285411508 \\
& -15.0650568078 & -42.9287834333 \\
& -15.063781528 & -42.9306277034 \\
Porteirinha & -15.7430555556 & -43.2830555556 \\
(MG) [42] & & \\
Urandi (BA) & -15.2777777778 & -43.0941666667 \\
{$[36,50]$} & -14.5 & -42.6833333333 \\
\hline
\end{tabular}

the first two discriminant factors. Mahalanobis distances were also computed from the same variables and used to illustrate morphological divergence among groups (species and sexes) by a dendrogram constructed according to the UPGMA algorithm. Statistical significance of these distances was assessed by non-parametric analyses based on permutation tests (1000 runs), and corrected by the Bonferroni method for $\mathrm{P} \leq 0.05$.

The residual relationship between shape and size variables was evaluated using a multivariate regression analysis of the first two shape discriminant factors against the centroid size values. This procedure allowed measurement of the contribution of size to shape variation (allometry), where statistical significance was assessed according to the non-parametric method based on permutation (1000 runs) [54].

We used the modules COO, TET, MOG, COV and PAD from the CLIC package (freely available at http:// mome-clic.com/) to collect landmarks, to compute centroid size and shape variables, as well as to evaluate the residual relationship between shape and size variables, and to generate discriminant models and Mahalanobis distances. For comparing overall wing size among groups and to elaborate quantile-plots of CS values, the lm function of $\mathrm{R}$ was used. The UPGMA dendrogram based on Mahalanobis distances was constructed using the neighbor module from the PHYLIP package (by Joe Felsenstein, available at http://evolution.genetics.washington.edu/phy lip.html).

\section{Molecular analysis}

Genomic DNA was extracted from individual specimen legs (stored at $-70{ }^{\circ} \mathrm{C}$ ) using the Wizard Genomic DNA Purification System (Promega, Madison, WI), re-suspended in $30 \mu$ of DNA Rehydration Solution (10 mM Tris pH 8.0, $1 \mathrm{mM}$ EDTA pH 8.0) and then stored at $-80^{\circ} \mathrm{C}$ until amplification by standard polymerase chain reaction (PCR). A fragment of $658 \mathrm{bp}$ in the $5^{\prime}$ end of the CO1 gene was amplified using the primers LCO 1490 (5'-GGTCAAC AAATCATAAAGATATTGG-3') and HCO 2198 (5' -TAA ACTTCAGGGTGACCAAAAAATCA-3') [55], following the thermal cycling conditions: an initial denaturation step at $94{ }^{\circ} \mathrm{C}$ for $3 \mathrm{~min}, 30$ cycles at $94{ }^{\circ} \mathrm{C}$ for $1 \mathrm{~min}, 45^{\circ} \mathrm{C}$ for $1 \mathrm{~min}$ and $72{ }^{\circ} \mathrm{C}$ for $1 \mathrm{~min}$, with a final extension at $72{ }^{\circ} \mathrm{C}$ for $10 \mathrm{~min}$. The $20 \mu \mathrm{l}$ PCR reaction mixes included $10 \mu \mathrm{l}$ of ultrapure water, $2 \mu \mathrm{l}$ of 10x PCR buffer, $0,8 \mu \mathrm{l}$ of each primer $(10 \mu \mathrm{M}), 2 \mu \mathrm{l}$ of dNTP $(2,5 \mathrm{mM}), 2 \mu \mathrm{l}$ of $\mathrm{MgCl} 2$ (50 mM), $0,4 \mu \mathrm{l}$ of Taq polymerase $(5 \mathrm{U} / \mu \mathrm{l})$ and $2 \mu \mathrm{l}$ of the DNA template $(10 \mathrm{ng} / \mu \mathrm{l})$. The PCR products were visualized on a $2 \%$ agarose gel and selected for direct sequencing, where both DNA strands were sequenced using the BigDye Terminator v3.1 Cycle Sequencing Kit (Applied Biosystems, Inc., Foster City, California, USA), following the manufacturer's protocol on an ABI 3730XL Automated DNA Analyzer (Applied Biosystems) available at the Oswaldo Cruz Institute, FIOCRUZ (Rio de Janeiro, Brazil).

All sequences were aligned with the Clustal W and edited using the Geneious R6 software (Biomatters Ltd, Auckland,

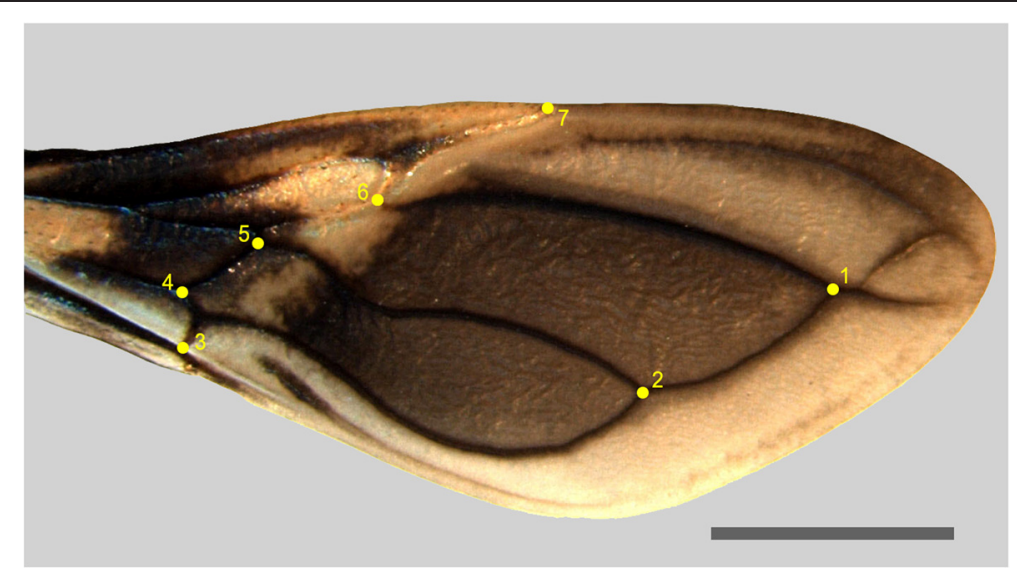

Fig. 1 Right wing of Triatoma melanica with the seven type I landmarks used in analysis. The same configuration was taken for $T$. brasiliensis. scale bar $=300 \mathrm{~mm}$ 
New Zealand $\left.{ }^{\circ}\right)$. The consensus sequences analysed in this study are deposited on GenBank under the accession numbers KJ580486 to KJ580495. Afterwards, we used MEGA v. 5.2 [56] to carry the sequence analyses. Intraspecific and interspecific genetic distances (sequence divergence) were calculated using the Kimura 2-Parameter (K2P) nucleotide substitution model [57]. In this approach, we also quantified the number of variables sites among sequences, as well as the nucleotide frequencies. A neighbor-joining (NJ) tree was constructed based on the K2P distances for representation of relationships among the analysed sequences, and the reliability of each node was estimated using the bootstrap method with 2,000 replicates. The tree was rooted using sequences of Triatoma sordida Stål, 1851 from Minas Gerais, Brazil (G. H. Campolina-Silva, unpublished data) as an outgroup.

All barcoded specimens have been deposited in the Coleção de Vetores da Doença de Chagas (COLVEC), Centro de Pesquisas René Rachou/FIOCRUZ.

\section{Ecological niche modelling}

Ecological niche modelling methods were used for the study of the geographic distribution of biological species in general and triatomines in particular [17, 58, 59], using environmental variables as proxies of species niche dimensions. Two main approaches were used as environmental data sources: the Worldclim database [60] and remotely sensed variables recorded by earth observation satellites.

Previously published studies on geographic distribution of the T. brasiliensis species complex $[10,12,17]$ used occurrence coordinates of specimens mainly collected during the 1980s and 1990s, before the species identification within the T. brasiliensis complex. To avoid confusion of occurrence points of possibly misclassified specimens, the present study of the geographic distribution of $T$. brasiliensis and T. melanica was based on an estimation of the environmental space from occurrence points where each species was collected either by our study group or taken from recent bibliographic records (15 for T. melanica and 140 for $T$. brasiliensis). The number of occurrence points in this study is smaller than the set analysed in previous studies (for example Costa et al. 2002) [61], as those studies used several occurrence points that in our consideration were initially identified as $T$. brasiliensis, but afterwards were synonymized to other specific names within the group complex. We used a set of occurrence points that have no possibility of taxonomic misidentification as T. brasiliensis brasiliensis. We consider that this conservative selection of occurrence points should show the distribution area of the species without errors. No absence points were used, but rather a random selection of 1000 background points. No biotic or abiotic barriers are known or can be imagined for the dispersion of the studied species, so that the accessible area for them is the whole study area. Although flying and/or walking are the most frequent mechanisms for active (and short ranged) dispersion in triatomines, passive dispersion (especially through human migrations) is the main mechanism for long range dispersion, as a number of very early studies demonstrated and recently confirmed using genetic markers [62].

A great variety of methods exist to estimate species distribution models. The maximum entropy is one of the most frequently used, because of the simplicity of use of the Maxent software. However, based on the simplicity criteria [63], the possibility of testing explicit assumptions, and on the equivalence between the results obtained using Maxent and Poisson point process models [64], we used a generalized linear model with a binomial link through the glm function of the R package.

A major objective of studies examining niche overlap is to determine if two species occupy the same niche. Even if two or more niches are identical, there will be some differences in the data purely by chance. To rule out detecting two niches as different, that actually only differ due to sampling variation, niche comparisons between two species must be done statistically to determine whether the same probability distribution describes the niche of two species, or whether there is evidence of some difference [65]. The estimated distribution models for the T. melanica and T. brasiliensis were compared using the Schoener index of niche overlap D, an index varying between $0-1$ (no niche overlap and identical niche, respectively), and used to perform niche equivalency and similarity tests [66]. We followed the framework proposed by Broennimann et al. (2012) [67] (based on Warren et al. 2008) [68], and specifically an ordination method (PCA-env) to estimate niche overlap, as the method disentangles the dependence of species occurrence from different climatic conditions (correcting for relative availability of environments) and from environmental data resolution. For the niche equivalency test all occurrences were pooled and randomly split into two datasets, maintaining the number of occurrences as in the original datasets, and the niche overlap statistic D was calculated. The process was repeated 100 times and a histogram of simulated values was constructed. If the observed value of D falls within the density of $95 \%$ of the simulated values, the null hypothesis of niche equivalency cannot be rejected. For the niche similarity test we randomly shift the entire observed density of occurrences in one range and calculate the overlap of the simulated niche with the observed niche in the other range. The test of niche similarity was also based on 100 repetitions. If the observed overlap is greater than $95 \%$ of the simulated values, the entity occupies environments in both of its ranges that are more similar to each 
other than expected by chance. All calculations were carried out using an R script produced by Broennimann et al. (2012) [67], and appropriately modified.

Environmental variables included in this study were day and night land surface temperature (LST) and vegetation index (NDVI) estimated from raster images produced by the MODIS sensor during the period 2009 - 2013 (downloaded as granules h12v09, h13v09, h13v10, h13v11, h14v09, h14v10, h14v11 from the http://e4ftl01.cr.usgs. gov/MOLT/ site); rainfall estimated by the Tropical Rainfall Measuring Mission (TRMM) during the period 2005 - 2013 (downloaded from the Goddard Earth Science site http://mirador.gsfc.nasa.gov/collections/TRMM_ 3B43_007.shtml) and elevation (produced by the Shuttle RT Mission and downloaded as a digital elevation model (DEM) from the CGIAR Consortium for Spatial Information at http://www.cgiar-csi.org/data/srtm-90m-digital-ele vation-database-v4-1). Temporal resolution was 8,16 and 30 days for LST, NDVI and rainfall, respectively. The spatial resolution at the data sources were $1 \mathrm{~km}$ for LST, 250 metres for NDVI, $0.5^{\circ}$ (nominally $25 \mathrm{kms}$ at the Equator) for rainfall and 90 metres for the DEM. All imagery was reprojected to a common geographic projection with WGS84 datum and resampled to 250 metres spatial resolution. As some points of triatomine collection were closer than $250 \mathrm{~m}$ apart, the number of occurrence points considered for T. melanica decreased to 8 and 132 for T. brasiliensis. A total of 200 images of LST (day and night) dates, 100 of NDVI dates and 108 monthly rainfall time series were processed calculating average and standard deviation of the time series for the period 2009-2013. The ecological niche model was thus based on 9 environmental predictors. A separate model for each species was calculated using the glm function of $\mathrm{R}$ version 3.0.2. Variables were selected to minimize the AIC (Akaike Information Criteria) using the stepAIC package. Colinearity among predictor variables was evaluated using the variance inflation factor (using vif function of the $\mathrm{R}$ car package) and a variable remained in the model if vif $<10$. Area under the receiver operation curve was calculated for model evaluation estimating partial AUC using the pROC package of $\mathrm{R}$ [69] that take into account the criticisms raised by Lobo et al. 2007 on the use of AUC [70]. Cross-validation (through the cv.glm function) was used to measure the robustness of model estimation, using $\mathrm{K}=100$ for $T$. brasiliensis and $\mathrm{K}=8$ for $T$. melanica.

\section{Results}

\section{Morphometric analysis}

As expected, there was a significant difference in centroid size values in both sexes and species $(\mathrm{P}<0.001)$ (Fig. 2). A consistent sexual size dimorphism was observed, where the female wings were larger than the males. Wing size was largest in T. brasiliensis, as observed by Costa and colleagues [42].

The first two discriminant factors (DF1 and DF2) explained $94 \%$ and $4 \%$ of wing shape variation, respectively. T. brasiliensis and T. melanica were significantly different $(\mathrm{P}<0.01)$ and well separated in a factorial map of discriminant analysis along the DF1 axis (Fig. 3a). T. melanica wings were narrow when compared with $T$.

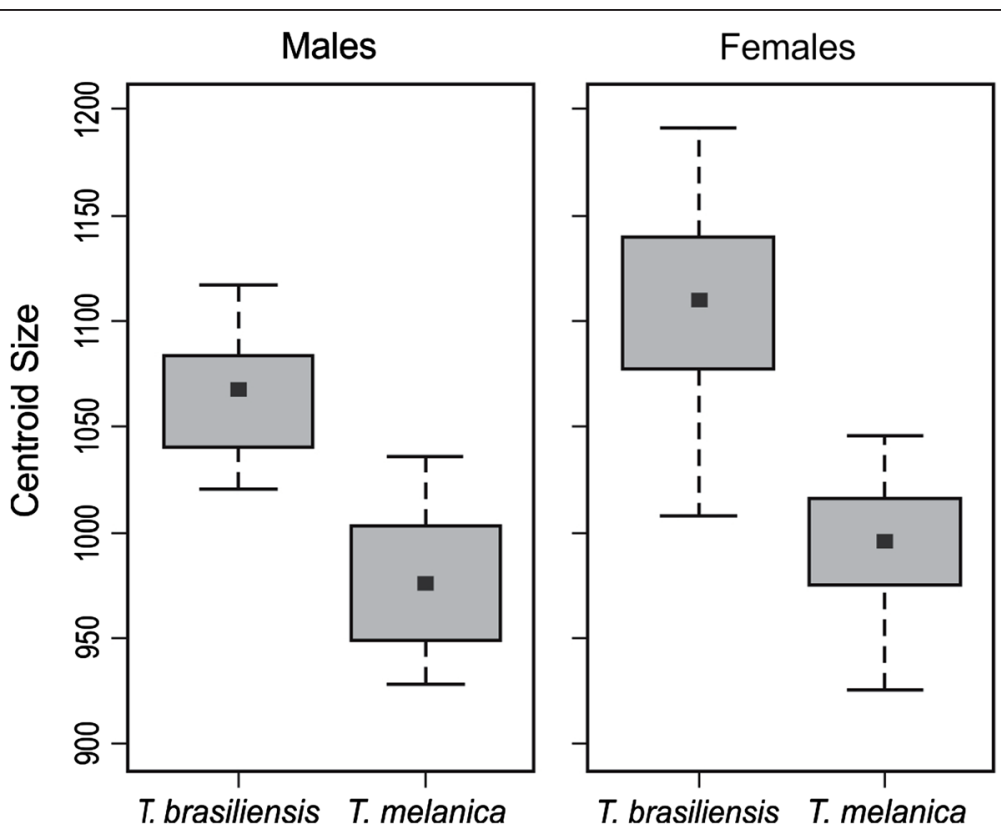

Fig. 2 Wing centroid size variation among males and females of T. brasiliensis and T. melanica. This shows the sexual size dimorphism. The group mean is shown as a box between the quartiles (25th and 75th percentiles) and the standard deviations are shown as lines. Units are pixels 

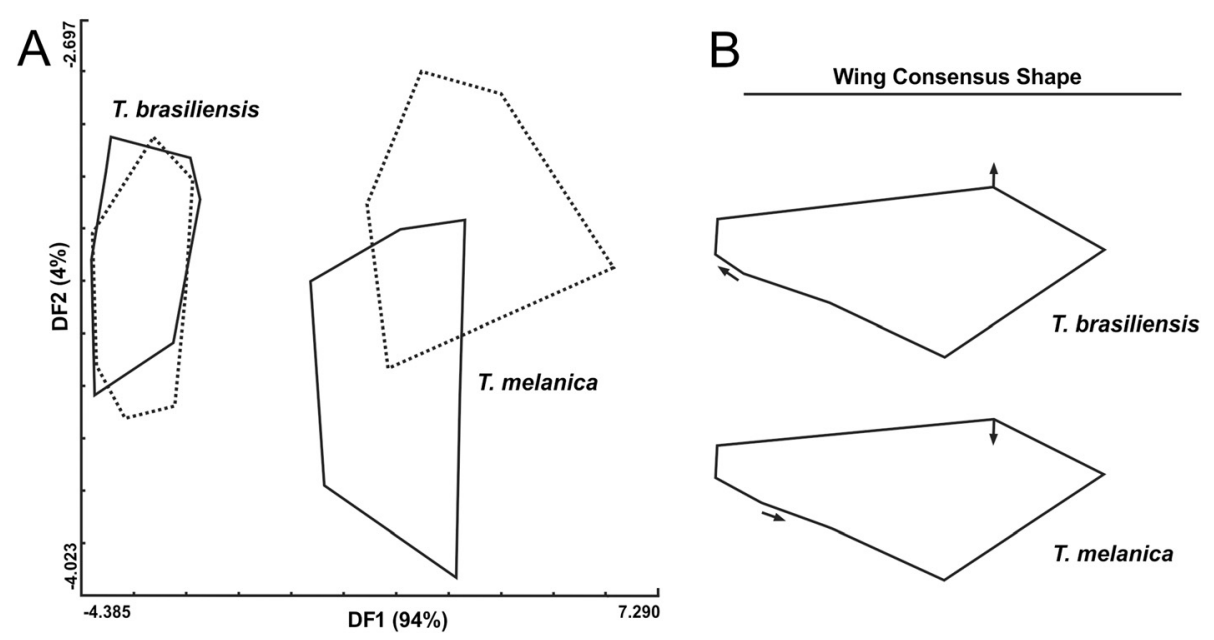

Fig. 3 Shape variation in T. brasiliensis and T. melanica. (A) Factorial map showing the distribution of specimens in the plane of the two discriminant factors derived from discriminant analysis of the shape variables. Polygons correspond to each group under study, where continuous polygons enclose males and dotted polygons enclose females. DF1 and DF2 are the first and second discriminate factors, and their corresponding percentage contribution to the total shape variation is shown in parentheses. (B) Wing consensus shape obtained after the Generalized Procrustes Analyses (GPA). Arrows indicate the major differences in wing shape of T. brasiliensis and T. melanica

brasiliensis, and the landmarks 3 and 7 better contributed to the conformational changes in wing venation (Fig. 3b), and are important in the discrimination of these species. Significant Mahalanobis distances could be found between species and sexes after the permutation test corrected by Bonferroni ( $\mathrm{P}<0.05)$, except for males and females of $T$. brasiliensis. The UPGMA dendrogram derived from these distances showed a clear separation between the species (Fig. 4). The multivariate regression analyses of the first two shape discriminant factors (DF1 and DF2) against the centroid size values revealed no significant contribution of size to shape variation (no allometric content, $\mathrm{p}=0.19$ ).

\section{DNA Barcoding analysis}

A total of $10 \mathrm{CO} 1$ sequences were generated. There were no detected insertions, deletions or presence of stop codons. The DNA barcode region analysed in this study comprised $564 \mathrm{bp}$, where the nucleotide composition between $T$. brasiliensis and T. melanica showed themselves to be similar, with an overall average of nitrogenous bases being $30.4 \%$ for Thymine (T), $28.1 \%$ for adenine (A), $24.4 \%$ for Cytosine (C), and $17.1 \%$ for Guanine (G). A total of 56 variation sites was observed (mainly at the third codon position) between the sequences, $55(98.2 \%)$ of these were partially informative and in $43(76.8 \%)$ there were fixed nucleotide substitutions, i.e. specific sites that are common to all sequences where there was exact replacement of a certain nucleotide between the two species. Transitions were more frequent than transversions (Table 2), with the transition $\mathrm{C} \leftrightarrow \mathrm{T}$ being the most commonly observed.

In order to evaluate the interspecific genetic divergence, the pairwise intra- and interspecific genetic distance (K2P) was calculated. The average intraspecific K2P distance was 0.006 , ranging from 0 to 0.009 in $T$. brasiliensis $(0.005 \pm \mathrm{SD} 0.002)$ and from 0.002 to 0.013 in T. melanica (0.008 \pm SD 0.004), whereas the average K2P distance between these two closely related species was fifteen times higher $(0.099 \pm \mathrm{SD} 0.003$, ranging from 0.094 to 0.103 ), supporting the barcoding gap, as proposed by Hebert and colleagues [71]. The values of the K2P distances are shown in Table 3.

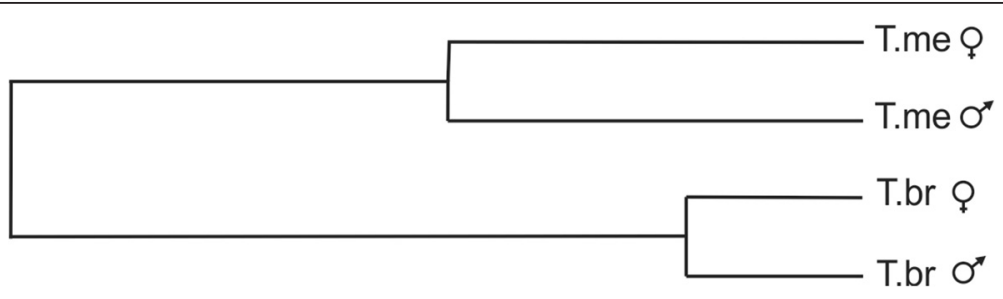

Fig. 4 UPGMA dendogram based on Mahalanobis distances derived from shape analyses. Observe a clear separation between T. melanica (T.me) and $T$. brasiliensis (T.br) 
Table 2 Summary of the variation along of the CO1 sequences analyzed

\begin{tabular}{lllll}
\hline & Nucleotides & Variables sites & TS & TV \\
\hline 1st & 188 & 13 & 9 & 0 \\
2nd & 188 & 14 & 10 & 3 \\
3rd & 188 & 29 & 18 & 3 \\
Total & 564 & 56 & 37 & 6 \\
\hline
\end{tabular}

Variables sites, transition and transversion rates among Triatoma brasiliensis

and Triatoma melanica. TS: number of transitions; TV: number of transversions

A neighbor-joining (NJ) tree constructed based on K2P distances (Fig. 5) shows two distinct clades strongly supported by a bootstrap value of $100 \%$, comprising a group formed by all $T$. brasiliensis individuals and another by $T$. melanica. Hence, our results indicate that these species might be recognized by the barcode region evaluated in this study.

\section{Geographic distributions}

The model estimating the distribution of $T$. brasiliensis $(\mathrm{n}=132)$ showed the average of LSTd and accumulated rainfall, and the variability of LSTd and LSTn and rainfall were all highly significant $(\mathrm{P}<0.001)$ in describing the species occurrence sites (Table 4). The occurrence chance of this species is positively related with LSTd and variability of LSTn, and negatively related with accumulated rainfall and variability of LSTd. Model fit is very good, with high partial AUC (pAUC) $=95 \%$ (CI95 of 91.3 - 97.2) and low cross validation error (0.041).

The model for T. melanica $(\mathrm{n}=8)$ showed that elevation, annual averages of LSTd, NDVI and variability of accumulated rainfall were the significant variables (Table 4). The occurrence chance of this species is positively related with elevation and averages of LSTd and NDVI, and negatively related with the variability of accumulated rainfall. Model fit was high, with pAUC $=98 \%$ (CI95 of $97.2-99.4)$ and low cross validation error $=0.0085$.
The model that predicts the potential distribution of $T$. brasiliensis identifies the main caatinga region as an area with similar environmental properties as the one where this specie was collected. The model for T. melanica predicts a sparse area towards the west (Goiás and Tocantins) and the northeast into the main caatinga region. Although map prediction identified different areas for the species, there are wide overlapping areas of model occurrence prediction. Figure 6 shows the prediction for the T. brasiliensis and T. melanica models, together with the area where the two models overlap.

Niche comparison using principal component analysis showed that the two first principal components explain $58 \%$ of the variation included in the 9 environmental variables used for the study. Niche overlap was estimated as $\mathrm{D}=0.291$. This value is larger than expected by chance, thus leading to acceptance of niche similarity $(\mathrm{P}>0.05)$, although leading to rejection of niche equivalency $(\mathrm{P}<0.05)$.

\section{Discussion}

Based on similarities in morphology, geographical distribution profile, epidemiological significance and phylogenetic relationships, a review [2] analyzing the systematics and evolution of the Triatominae subfamily, list the probable existence of 8 species complexes within the genus Triatoma Laporte, 1832. Among these, the T. brasiliensis complex has been continuously evaluated and is currently composed by T. melanica, T. juazeirensis, T. sherlocki and T. brasiliensis, the latter having two subspecies, T. brasiliensis brasiliensis and T. brasiliensis macromelasoma [12].

Among the five members of this complex, the subspecies $T$. b. brasiliensis has been considered as the main concern in terms of Chagas disease transmission, because this subspecies is the most widespread and shows the highest rate of domestic capture and of natural infection by $T$. cruzi $[9,10]$. On the other hand, to date,

Table 3 Pairwise intra and interspecific genetic distances, based on the Kimura 2-Parameter model

\begin{tabular}{|c|c|c|c|c|c|c|c|c|c|c|}
\hline SAMPLES & 1 & 2 & 3 & 4 & 5 & 6 & 7 & 8 & 9 & 10 \\
\hline 1. T.me (KJ580495) & - & & & & & & & & & \\
\hline 2. T.me (KJ580494) & 0,002 & - & & & & & & & & \\
\hline 3. T.me (KJ580493) & 0,011 & 0,013 & - & & & & & & & \\
\hline 4. T.me (KJ580492) & 0,009 & 0,011 & 0,002 & - & & & & & & \\
\hline 5. T.br (KJ580490) & 0,101 & 0,101 & 0,099 & 0,099 & - & & & & & \\
\hline 6. T.br (KJ580486) & 0,103 & 0,103 & 0,101 & 0,101 & 0,002 & - & & & & \\
\hline 7. T.br (KJ580488) & 0,103 & 0,103 & 0,101 & 0,101 & 0,005 & 0,004 & - & & & \\
\hline 8. T.br (KJ580491) & 0,101 & 0,101 & 0,099 & 0,099 & 0 & 0,002 & 0,005 & - & & \\
\hline 9. T.br (KJ580487) & 0,097 & 0,096 & 0,094 & 0,094 & 0,007 & 0,005 & 0,009 & 0,007 & - & \\
\hline 10. T.br (KJ580489) & 0,097 & 0,096 & 0,094 & 0,094 & 0,007 & 0,005 & 0,009 & 0,007 & 0 & - \\
\hline
\end{tabular}

T.me: Triatoma melanica; T.br: Triatoma brasiliensis. The numbers inside the parentheses correspond to the GenBank accession numbers 


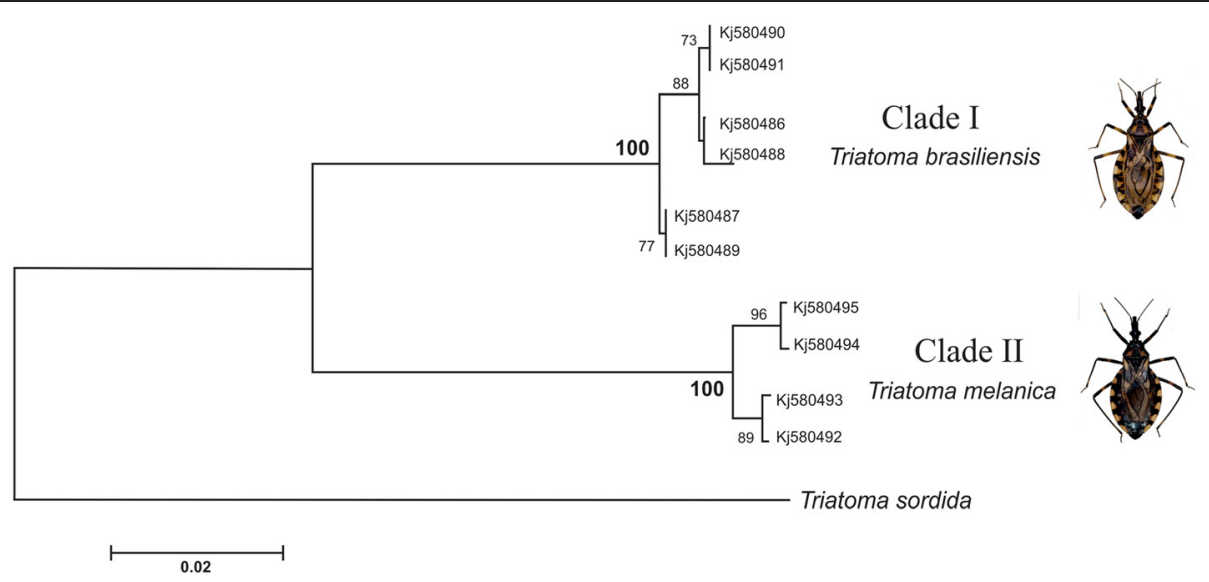

Fig. 5 Neighbor-joining tree based on K2P distances of CO1 sequences from T. brasiliensis and T. melanica. The NJ tree was rooted using sequences of Triatoma sordida and the bootstrap value of 2,000 replicates is shown on each node. Scale bar $=0.02$

T. melanica has been found almost exclusively in wild environments, and collected specimens have been shown to be restricted to municipalities in the northern region of Minas Gerais and the southern region of Bahia [12].

Analysis involving Triatominae mtDNA sequences are regularly used in order to elucidate phylogenetic relationships among closely related Triatominae species. In this respect, the most widely used markers include fragments of gene encoding proteins such as cytochrome b $[11,34,36,72,73]$ and subunits of ribosomal RNA (12S and 16S) [33, 74-76]. The present study shows the effectiveness of DNA barcoding in identifying species of the $T$. brasiliensis complex and reinforces its contribution to classic taxonomy. The analyzed CO1 fragment was sufficient to discriminate $T$. brasiliensis and T. melanica, showing that these species are separated by a large genetic distance. The discrimination of these species can be well represented by the NJ tree with bootstrap values

Table 4 Generalised linear model fit

\begin{tabular}{llll}
\hline Triatoma brasiliensis & \multicolumn{4}{l}{ Triatoma melanica } \\
\hline Coefficient & Estimate & Coefficient & Estimate \\
Intercept & $-1.96 \mathrm{e}+02^{* * *}$ & Intercept & $-6.527 \mathrm{e}+02^{* * *}$ \\
AVGLSTD & $1.038 \mathrm{e}-02^{* * *}$ & AVGLSTD & $4.126 \mathrm{e}-02^{* * *}$ \\
SDAVGLSTD & $-4.507 \mathrm{e}-04^{* * *}$ & AVGNDVI & $2.916 \mathrm{e}-03^{* *}$ \\
SDAVGLSTN & $8.526 \mathrm{e}-04^{* * *}$ & SDAVGRAIN & $-2.154 \mathrm{e}-02^{*}$ \\
AVGRAIN & $-3.291 \mathrm{e}-03^{* * *}$ & DEM & $1.430 \mathrm{e}-02^{* * *}$ \\
AUC & 0.976 & & 0.989 \\
Cross Validation & 0.0409 & & 0.00854
\end{tabular}

Geographic distribution of T. brasiliensis (132 occurrence points), T. melanica (8 occurrence points) and 1000 (independent for each model) background points. The remotely sensed environmental variables are AVGLSTD (average of diurnal land surface temperature), AVGRAIN (average of annual accumulated rainfall), AVGNDVI (NDVI average), DEM (elevation), SDAVGLSTD and SDAVGLSTN (standard deviation of diurnal and nocturnal land surface temperature, respectively), SDAVGRAIN (standard deviation of annual accumulated rainfall). ${ }^{*} \mathrm{P}<0.05 ;{ }^{* * P}<0.01,{ }^{* * *} \mathrm{P}<0.001$ of $100 \%$ for the two identified clades. This shows that our analysis of pair wise distance-based K2P within the T. brasiliensis complex supported a clear barcoding gap between the intra- and interspecific variation [76].

In a recent study, Justi et al. conclude that DNA barcoding is not applicable for the identification of Southern American Triatoma species, which may have diverged recently, because they observed at least one intraspecific genetic distance greater than interspecific distance in assessed species [77]. The authors mention that to be considered appropriate to identify species, intraspecific distances must always be lower than interspecific ones. Unlike the findings of Justi et al., the results of this study show that the $\mathrm{CO} 1$ barcode region is a robust marker for differentiating this species complex, and it may constitute a valuable tool for both epidemiologic studies and for Chagas disease control, including subspecies differentiation, as observed by Vendrami et al. [49]. Furthermore, this methodology can be especially useful for identifying immature stages, whose traditional taxonomic method is made impossible in smaller nymphs, especially considering the species complexes that exhibit wide morphological and chromatic variation.

The barcode sequences result found is congruent with the geometric morphometric analysis. Centroid size variation was as significant in the interspecific analysis as it was in the separation between males and females. Size variation related to gender, with females of both species larger than males, was expected with the presence of sexual dimorphism being a known characteristic in triatomines [78]. The morphometric analyses of wing was able to discriminate the two members of the complex (DF1 = 94. \%), allowing assignment without error of each single wing to its corresponding taxon, and producing a pattern of relationships in agreement within known genetic distances between populations, as observed by Costa and 


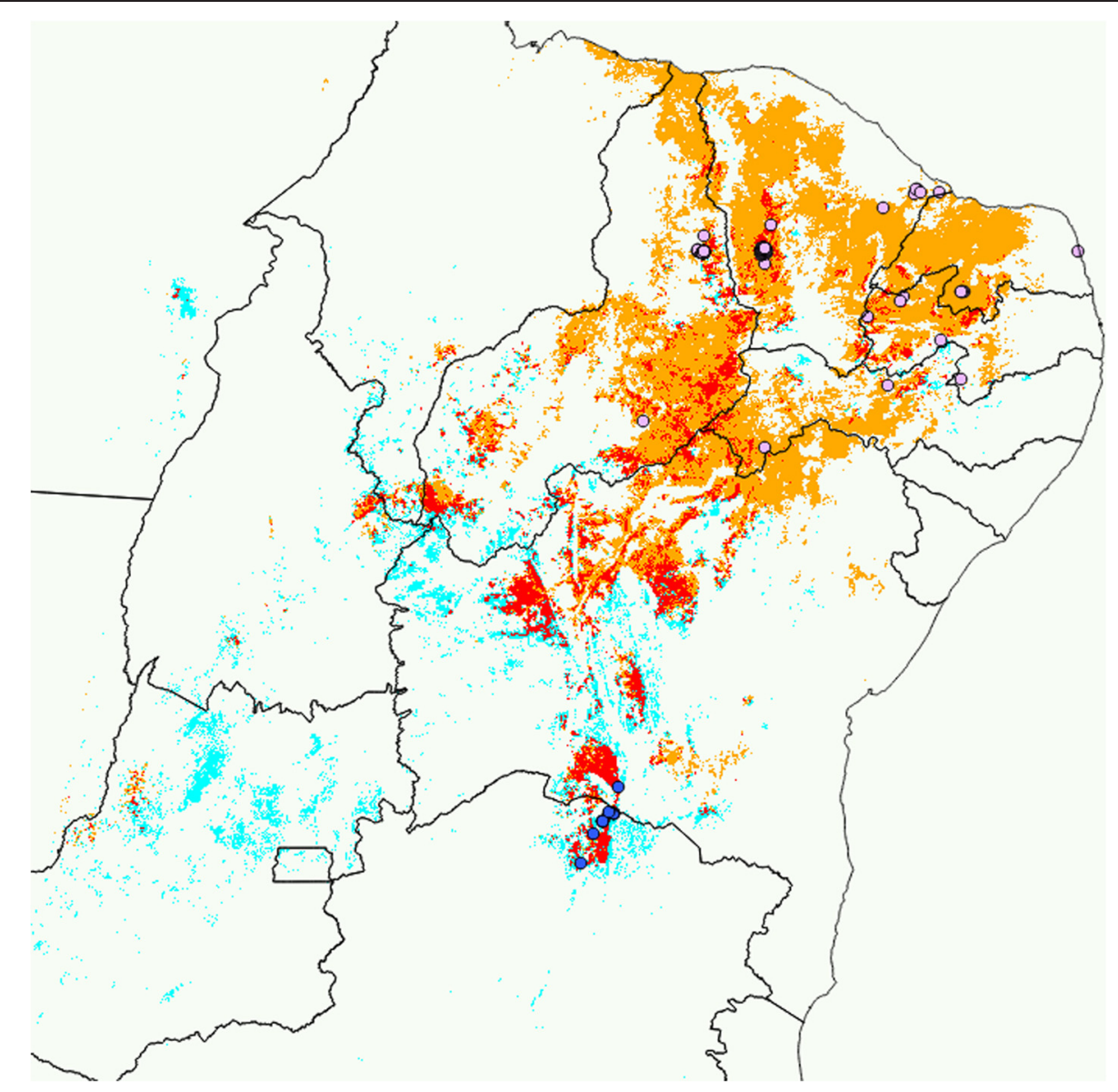

Fig. 6 Modeling Disease Vector Occurrence. Geographic distribution of T. brasiliensis (orange), T. melanica (light blue) estimated by the generalized linear model for each species, and area where both models overlap (red). T. brasiliensis occurrence points (pink circles) and T. melanica occurrence points (blue circles)

colleagues [42]. As a result of there being no allometric trends for wing shape comparisons between $T$. brasiliensis and T. melanica, it is suggested that the change in this structure's shape should mainly reflect the variation of genetic origin [69]. Furthermore, the recorded sexual dimorphism suggests stability and adaptation of both species to the sylvatic ecotope, without evidence of exposure to environmental stress conditions, which may lead to reduction in size of females, as proposed by Dujardin et al. 1999 [79].

The ecological niche model using elevation and current data on land surface temperature, vegetation cover and rainfall showed that elevation, the average of LSTd, accumulated rainfall and variability of LSTd and LSTn are the environmental variables that best describe the geographic distribution of $T$. brasiliensis, whereas elevation, the average of LST, NDVI and variability of accumulated rainfall are the ones best describing the distribution of $T$. melanica. The result for T. melanica is probably less reliable, because of the small sample size of occurrence points, and restricted to a small area. Conversely, the prediction map for $T$. brasiliensis is very reliable, and indicates a potential distribution particularly associated with the caatinga biome. Of particular importance for the objective of this study is the niche comparison between the species. Results show that niches are similar but not equivalent, suggesting that $T$. brasiliensis and T. melanica share similar environmental constraints but that a different set of variables within the environmental niche space restrict their distribution. It is interesting that the model for $T$. brasiliensis predicts occurrence where T. melanica was collected, and the model of T. melanica predicts occurrence (although loosely) where $T$. brasiliensis was collected. Both species are associated with the caatinga region and have rupicolous habits. No difference between the species at the microscale is expected within the macro landscape of the caatinga, but this is an aspect that should be verified under field conditions. In evolutionary terms, the results of this study suggest that the separation in two different species should be attributed to a factor that does not 
include the current environmental conditions. However, as the caatinga is a biome that has existed in the area for at least the last 18,000 years [80, 81], past conditions might have had an influence in the speciation process.

The potential geographic distribution maps obtained differed with previously published studies $[17,82]$. The differences are attributed to a) our use of a different set of occurrence points of specimens, based on criteria of minimum chance of species misidentification, a weakness that old records, previous to the species identification within the $T$. brasiliensis complex might possess, b) our use of current environmental conditions of temperature, vegetation and rainfall (measured by sensors onboard earth observation satellites, reflecting the land cover situation within the last 5 years of an area that shows an important landscape modification within the last 20 years), instead of the Bioclim database [60] that reflect past conditions (averaged between 1950-2000), through an interpolation process of ground meteorological stations, that in the area were extremely sparse during the considered period and might produce low reliability for the temperature and rainfall variables for the area, and c) our approach used for the whole study area as potentially accessible by the species, without imposing political boundary limits to map predictions.

Despite the successful vector control programme of Triatoma infestans in most parts of the southern cone countries of South America, native vectors persistently reinfest insecticide-treated households, and sylvatic triatomines maintain disease transmission without colonizing human dwellings. In these scenarios, fine-scale vector studies are essential to define epidemiological risk patterns and clarify the involvement of the little-known triatomine taxa in disease transmission. These eco-epidemiological investigations, as well as the planning and monitoring of control interventions, rely on accurate taxonomic judgments. The problems of cryptic speciation and phenotypic plasticity illustrate this need.

\section{Conclusion}

Although DNA barcoding is a straightforward approach, it is applicable for identifying species of the $T$. brasiliensis complex and contributes to classic taxonomy. The analyses of wing shape was able to differentiate the two members of the complex, and showed that the species are not under stressful conditions. As a result of there being no allometric trends in the wing shape comparison between T. brasiliensis and T. melanica, it is suggested that the change in this structure's shape should mainly reflect the variation of genetic origin. In evolutionary terms, the result of the environmental niche space occupied by the studied species suggests that their separation as two different entities should be attributed to a factor that does not include the current environmental conditions. However, as the caatinga is a biome that has existed in the area for at least the last 18,000 years, past conditions might have had an influence in the speciation process.

\section{Competing interests}

The authors declare that they have no competing interests.

\section{Authors' contributions}

All the authors have contributed substantially to this study. RCMS and LD designed the study. RCMS, GHCS, CMB acquired data. RCMS, GHCS, LD, DG performed all the analyses, interpreted the results, drafted and reviewed the manuscript. All authors read and approved the final version of the manuscript.

\section{Acknowledgements}

This study makes up part of the results reached by the Brazilian Network for Molecular Identification of Biodiversity (Br-Bol), financed by the National Council for Scientific and Technological Development (CNPq) through public notice 50/2010 PPBio. We acknowledge the Ciências sem Fronteiras (CNPq) programme that supported the working periods of DEG at FIOCRUZ-MG. We would like to thank Dr. Karina Alessandra Morelli, who was responsible for the Molecular Identification Platform of Parasites and Vectors, for her help and clarification; Raíssa Nogueira Brito and Juliana Assis Geraldo for their support in the analyses; the PCDCh health workers for their help in capturing the triatomines.

\section{Author details}

'Laboratório de Triatomíneos e Epidemiologia da Doença de Chagas, Centro de Pesquisas René Rachou, Fundação Oswaldo Cruz, CEP 30.190-002 Belo Horizonte, Minas Gerais, Brazil. 'Secretaria de Saúde do Estado do Ceará, Fortaleza, Ceará, Brazil. "3IMBIV-CONICET, Casilla de Correo 495, 5000 Córdoba, Argentina.

Received: 22 May 2015 Accepted: 30 June 2015

Published online: 10 July 2015

\section{References}

1. Rassi Jr A, Rassi A, Marin-Neto JA. Chagas disease. Lancet. 2010;375:1388-402.

2. Schofield CJ, Galvão C. Classification, evolution, and species groups within the Triatominae. Acta Trop. 2009;110:88-100.

3. Frias-Lasserre D. A new species and karyotype variation in the bordering distribution of Mepraia spinolai (Porter) and Mepraia gajardoi Frias et al. (Hemiptera: Reduviidae: Triatominae) in Chile and its parapatric model of speciation. Neotrop Entomol. 2010;39:572-83.

4. Rosa JA, Rocha CS, Gardim S, Pinto MC, Mendonça VJ, Ferreira Filho JCR, et al. Description of Rhodnius montenegrensis n. sp. (Hemiptera: Reduviidae: Triatominae) from the state of Rondônia, Brazil. Zootaxa. 2012;3478:62-76.

5. Abad-Franch F, Pavan MG, Jaramillo ON, Palomeque FS, Dale C, Chaverra D, et al. Rhodnius barretti, a new species of Triatominae (Hemiptera: Reduviidae) from western Amazonia. Mem Inst Oswaldo Cruz. 2013;108:92-9.

6. Gonçalves TC, Teves-Neves SC, Santos-Mallet JR, Carbajal-de-la-Fuente AL, Lopes CM. Triatoma jatai sp. nov. in the state of Tocantins, Brazil (Hemiptera: Reduviidae: Triatominae). Mem Inst Oswaldo Cruz. 2013;108:429-37.

7. Jurberg J, Cunha V, Cailleaux S, Raigorodschi R, Lima MS, Rocha DS, et al. Triatoma pintodiasi sp. nov. do subcomplexo T. rubrovaria (Hemiptera: Reduviidae: Triatominae). Pan-Amaz Saude. 2013:4:43-56.

8. Poinar Jr GO. Panstrongylus hispaniolae sp. n. (Hemiptera: Reduviidae: Triatominae), a new fossil triatomine in Dominican amber, with evidence of gut flagellates. Palaeodiversity. 2013;6:1-8.

9. Silveira AC, Vinhaes MC. Elimination of vector-borne transmission of Chagas disease. Mem Inst Oswaldo Cruz. 1999;94:405-11.

10. Costa J, Almeida CE, Dotson EM, Lins A, Vinhaes M, Silveira AC, et al. The epidemiologic importance of Triatoma brasiliensis as a Chagas disease vector in Brazil: a revision of domiciliary captures during 1993-1999. Mem Inst Oswaldo Cruz. 2003;98:443-9.

11. Monteiro FA, Donnelly MJ, Beard CB, Costa J. Nested clade and phylogeographic analyses of the Chagas disease vector Triatoma brasiliensis in Northeast Brazil. Mol Phylogenet Evol. 2004;32:46-56.

12. Costa J, Correia NC, Neiva VL, Goncalves TC, Felix M. Revalidation and redescription of Triatoma brasiliensis macromelasoma Galvão, 1956 and an identification key for the Triatoma brasiliensis complex (Hemiptera: Reduviidae: Triatominae). Mem Inst Oswaldo Cruz. 2013;108:785-9. 
13. Morel CM, Lazdins J. Chagas disease. Nat Rev Microbiol. 2003;1:14-5.

14. Schofield CJ, Jannin J, Salvatella R. The future of Chagas disease control. Trends Parasitol. 2006;22:583-8.

15. Lima MM, Sarquis O. Is Rhodnius nasutus (Hemiptera; Reduviidae) changing its habitat as a consequence of human activity? Parasitol Res. 2008;102:797-800

16. Silveira AC, Dias JCP. O controle da transmissão vetorial. Rev Soc Bras Med Trop. 2011;44:52-63.

17. Gurgel-Gonçalves R, Galvão C, Costa J, Peterson AT. Geographic distribution of Chagas disease vectors in Brazil based on ecological niche modeling. J Trop Med. 2012:ID705326. doi: 10.1155/2012/705326. Epub 2012 Feb 27

18. Abad-Franch F, Monteiro FA. Molecular research and the control of Chagas disease vectors. An Acad Bras Cienc. 2005:77:437-54.

19. Henry A, Thongsripong P, Fonseca-Gonzalez I, Jaramillo NO, Dujardin JP. Wing shape of dengue vectors from around the world. Inf Gen Evol. 2010;10:207-14.

20. Baylac M, Villemant C, Simbolotti G. Combining geometric morphometrics with pattern recognition for the investigation of species complexes. Biol J Linn Soc. 2003;80:89-98.

21. Matias A, de la Rive JX, Torrez M, Dujardin JP. Rhodnius robustus in Bolivia identified by its wings. Mem Inst Oswaldo Cruz. 2001;96:947-50.

22. Abad-Franch F, Monteiro FA, Jaramillo N, Gurgel-Gonçalves R, Dias FBS, Diotaiuti L. Ecology, evolution, and the long-term surveillance of vector-borne Chagas disease: A multi-scale appraisal of the tribe Rhodniini (Triatominae). Acta Trop. 2009;110:159-77.

23. Villegas J, Feliciangeli MD, Dujardin JP. Wing shape divergence between Rhodnius prolixus from Cojedes (Venezuela) and Rhodnius robustus from Merida (Venezuela). Infect Genet Evol. 2002;2:121-8.

24. Calle D, Quiñones ML, Erazo HF, Jaramillo N. Morphometric Discrimination of Females of Five Species of Anopheles of the Subgenus Nyssorhynchus from Southern and Northwest Colombia. Mem Inst Oswaldo Cruz 2002;97:1191-5.

25. Dujardin JP, Le Pont F, Baylac M. Geographic versus interspecific differentiation of sandflies: a landmark data analysis. Bull Entomol Res. 2003;93:87-90

26. Gumiel M, Catala S, Noireau F, De Arias AR, Garcia A, Dujardin JP. Wing geometry in Triatoma infestans (Klug) and T. melanosoma Martinez, Olmedo \& Carcavallo (Hemiptera: Reduviidae). Syst Entomol. 2003;28:173-9.

27. Vargas E, Espitia C, Patino C, Pinto N, Aguilera G, Jaramillo C, et al. Genetic structure of Triatoma venosa (Hemiptera:Reduviidae): molecular and morphometric evidence. Mem Inst Oswaldo Cruz. 2006;101:39-45.

28. Dujardin JP, Beard CB, Ryckman R. The relevance of wing geometry in entomological surveillance of Triatominae, vectors of Chagas disease. Inf Gen Evol. 2007;7:161-7.

29. Feliciangeli MD, Sanchez-Martin M, Marrero R, Davies C, Dujardin JP. Morphometric evidence for a possible role of Rhodnius prolixus from palm trees in house re-infestation in the State of Barinas (Venezuela). Acta Trop. 2007:101:169-77.

30. Gurgel-Gonçalves R, Abad-Franch F, Ferreira JB, Santana DB, Cuba CA. Is Rhodnius prolixus (Triatominae) invading houses in central Brazil? Acta Trop. 2008;107:90-8.

31. Gurgel-Gonçalves R, Ferreira JB, Rosa AF, Bar ME, Galvão C. Geometric morphometrics and ecological niche modelling for delimitation of near-sibling triatomine species. Med Vet Entomol. 2011;25:84-93.

32. Hebert PD, Cywinska A, Ball SL, De Waard JR. Biological identifications through DNA barcodes. Proc Biol Sci. 2003;270:313-21.

33. Garcia BA, Powell JR. Phylogeny of species of Triatoma (Hemiptera: Reduviidae) based on mitochondrial DNA sequences. J Med Entomol. 1998;35:232-8.

34. Pfeiler E, Bitler BG, Ramsey JM, Palacios-Cardiel C, Markow TA. Genetic variation, population structure, and phylogenetic relationships of Triatoma rubida and $T$. recurva (Hemiptera: Reduviidae: Triatominae) from the Sonoran Desert, insect vectors of the Chagas' disease parasite Trypanosoma cruzi. Mol Phylogenet Evol. 2006;41:209-21.

35. Cortez MR, Emperaire L, Piccinali RV, Gurtler RE, Torrico F, Jansen AM, et al. Sylvatic Triatoma infestans (Reduviidae, Triatominae) in the Andean valleys of Bolivia. Acta Trop. 2007;102:47-54.

36. Gardim S, Almeida CE, Takiya DM, Oliveira J, Araújo RF, Cicarelli RMB, et al. Multiple mitochondrial genes of some sylvatic Brazilian Triatoma: Nonmonophyly of the T. brasiliensis subcomplex and the need for a generic revision in the Triatomini. Inf Gen Evol. 2014;23:74-9.

37. Hajibabei M, Janzen DH, Burns JM, Hallwachs W, Hebert PD. DNA barcodes distinguish species of tropical Lepidoptera. Proc Natl Acad Sci U S A. 2006;103:968-71
38. Cywinska A, Hunter FF, Hebert PD. Identifying Canadian mosquito species through DNA barcodes. Med Vet Entomol. 2006;20:413-24.

39. Park DS, Foottit R, Maw E, Hebert PD. Barcoding bugs: DNA-based identification of the true bugs (Insecta: Hemiptera: Heteroptera). PLoS One. 2006;6, e18749.

40. Scarpassa VM, Alencar RB. Molecular taxonomy of the two Leishmania vectors Lutzomyia umbratilis and Lutzomyia anduzei (Diptera: Psychodidae) from the Brazilian Amazon. Parasit Vectors. 2013;6:258.

41. Rebijith KB, Asokan R, Kumar NK, Krishna V, Chaitanya BN.

42. Costa J, Peterson AT, Dujardin JP. Morphological evidence suggests homoploid hybridization as a possible mode of speciation in the Triatominae (Hemiptera, Heteroptera, Reduviidae). Inf Gen Evol. 2009;9:263-70.

43. Batista VSP, Fernandes FA, Cordeiro-Estrela P, Sarquis O, Lima MM. Ecotope effect in Triatoma brasiliensis (Hemiptera: Reduviidae) suggests phenotypic plasticity rather than adaptation. Med Vet Entomol. 2013;27(3):247-54.

44. Sarquis O, Carvalho-Costa FA, Oliveira LS, Duarte R, D'Andrea PS, Oliveira TG, et al. Ecology of Triatoma brasiliensis in northeastern Brazil: seasonal distribution, feeding resources, and Trypanosoma cruzi infection in a sylvatic population. J Vec Ecol. 2010;35(2):385.

45. Velença-Barbosa C, Lima MM, Sarquis O, Bezerra CM, Abad-Franch F. Modeling Disease Vector Occurrence When Detection Is Imperfect II: Drivers of SiteOccupancy by Synanthropic Triatoma brasiliensis in the Brazilian Northeast. PLoS Negl Trop Dis. 2014;8(5), e2861.

46. Borges EC, Dujardin JP, Schofield CJ, Romanha AJ, Diotaiuti L. Dynamics between sylvatic, peridomestic and domestic populations of Triatoma brasiliensis (Hemiptera: Reduviidae) in Ceará State, Northeastern Brazil. Acta Tropica. 2005;93:119-26.

47. Sarquis O, Carvalho-Costa FA, Toma HK, Georg I, Burgoa MR, Lima MM. Ecoepidemiology of Chagas disease in northeastern Brazil: Triatoma brasiliensis, T. pseudomaculata and Rhodnius nasutus in the sylvatic, peridomestic and domestic environments. Parasitol Res. 2012:110:1481-5.

48. Câmara ACJ, Varela-Freire AA, Valadares HMS, Macedo AM, D'Ávila DA, et al. Genetic analyses of Trypanosoma cruzi isolates from naturally infected triatomines and humans in northeastern Brazil. Acta Tropica. 2010;115:205-11.

49. Vendrami DP, Ceretti-Junior W, Obara MT, Marrelli MT. Mitochondrial PCR-RFLP Assay to Distinguish Triatoma brasiliensis macromelasoma from Triatoma brasiliensis brasiliensis Subspecies (Hemiptera: Reduviidae). J Trop Med. 2013;ID 305198:7.

50. Correia N, Almeida CE, Lima-Neiva V, Gumiel M, Dornak LL, Lima MM, et al. Cross-mating experiments detect reproductive compatibility between Triatoma sherlocki and other members of the Triatoma brasiliensis species complex. Acta Trop. 2013;128:162-7

51. Bookstein FL. Morphometric Tools for Landmark Data: Geometry and Biology. Cambridge UK: Cambridge University Press; 1991.

52. Rohlf FJ. Morphometric spaces, shape components and the effects of linear transformations. In Advances in Morphometrics. Plenum Publication. Edited by Marcus LF, Corti M, Loy A, Naylor GJP, Slice D. NATO ASI, Series A Life Sciences. N Y. 1996;117-129.

53. Zelditch ML, Swiderski DL, Sheets HD, Fink WL. Geometric Morphometrics for Biologists: A Primer. Edited by Elsevier. New York: Academic; 2004.

54. Good P. Permutation Tests: A Practical Guide to Resampling Methods for Testing Hypotheses. Edited by Springer. Universidade de Michigan: Academic Press. Hardin JW: Springer series in Statistics, 2a Ed; 2000.

55. Folmer O, Black M, Hoeh W, Lutz R, Vrijenhoek R. DNA primers for amplification of mitochondrial cytochrome c oxidase subunit I from diverse metazoan invertebrates. Mol Mar Biol Biotechnol. 1994:3:294-9.

56. Tamura K, Peterson D, Peterson N, Stecher G, Nei M, Kumar S. MEGA5: molecular evolutionary genetics analysis using maximum likelihood, evolutionary distance, and maximum parsimony methods. Mol Biol Evol. 2011;28:2731-9.

57. Kimura M. A simple method for estimating evolutionary rates of base substitutions through comparative studies of nucleotide sequences. J Mol Evol. 1980;16:111-20

58. Gorla DE. Variables ambientales registradas por sensores remotos como indicadores de la distribucíon geográfica de Triatoma infestans (Heteroptera: Reduviidae). Ecol Austral. 2002;2:117-27.

59. de La Fuente AL C, Porcasi X, Noireau F, Diotaiuti L, Gorla D, et al. The association between the geographic distribution of Triatoma pseudomaculata and Triatoma wygodzinskyi (Hemiptera: Reduviidae) with environmental variables recorded by remote sensors. Inf Gen Evol.

60. Hijmans RJ, Cameron SE, Parra JL, Jones PG, Jarvis A. Very high resolution interpolated climate surfaces for global land areas. Int J Climatol. 2005:25:1965-78. 
61. Costa J, Peterson A, Beard C. Ecologic niche modeling and differentiation of populations of Triatoma brasiliensis Neiva, 1911, the most important Chagas' disease vector in northeastern Brazil (Hemiptera, Reduviidae, Triatominae). Am J Trop Med Hyg. 2002;67:516-20.

62. Piccinali RV, Canale DM, Sandoval AE, Cardinal MV, Jensen O, Kitron U, et al. Triatoma infestans bugs in Southern Patagonia, Argentina Emerging. Inf Diseases. 2010;16:887-9.

63. Merow C, Smith MJ, Edwards TC, Guisan A, McMahon SM, Normand S, et al. What do we gain from simplicity versus complexity in species distribution models? Ecography. 2014;37:1267-81.

64. Renner IW, Warton DI. Equivalence of MAXENT and Poisson point process models for species distribution modeling in ecology. Biometrics. 2013;69:274-81.

65. Geange SW, Pledger S, Burns KC, Shima JS. A unified analysis of niche overlap incorporating data of different types. Meth Ecol Evol. 2011;2:175-84.

66. Schoener TW. No synchronous spatial overlap of lizards in patchy habitats. Ecology. 1970;51:408-18.

67. Broennimann O, Fitzpatrick MC, Pearman PB, Petitpierre B, Pellissier L, Yoccoz NG, et al. Measuring ecological niche overlap from occurrence and spatial environmental data. Global Ecol Biogeography. 2012;21:481-97.

68. Warren DL, Glor RE, Turelli M. Environmental niche equivalency versus conservatism: quantitative approaches to niche evolution. Evolution. 2008;62:2868-83.

69. Robin X, Turck N, Hainard A, Tiberti N, Lisacek F, Sanchez JC, et al. pROC: an open-source package for $\mathrm{R}$ and $\mathrm{S}+$ to analyze and compare ROC curves. BMC Bioinformatics. 2011;12:77.

70. Lobo JM, Jiménez-Valverde A, Real R. AUC: a misleading measure of the performance of predictive distribution models. Glob Ecol Biogeo. 2008;17:145-51.

71. Hebert PD, Stoeckle MY, Zemlak TS, Francis CM. Identification of Birds through DNA Barcodes. PLoS Biol. 2004;2, e312.

72. Monteiro FA, Perez R, Panzera F, Dujardin JP, Galvão C, Rocha DS, et al Mitochondrial DNA Variation on Triatoma infestans populations and its implication on the specific status of T. melanosoma. Mem Inst Oswaldo Cruz. 1999;94:851-954.

73. Monteiro FA, Barret TV, Fitzpatrick S, Cordon-Rosales C, Feliciangeli D, Beard CB. Molecular phylogeography of the Amazonian Chagas disease vectors Rhodnius prolixus and R. robustus. Mol Ecol. 2003;12:997-1006.

74. Garcia BA, Moriyama EN, Powell JR. Mitochondrial DNA sequences of triatomines (Hemiptera: Reduviidae): phylogenetic relationships. J Med Entomol. 2011;38:675-83.

75. Hypša V, Tietz DF, Zrzavy J, Rego ROM, Galvão C, Jurberg J. Phylogeny and biogeography of Triatominae (Hemiptera: Reduviidae): molecular evidence of a New World origin of the Asiatic clade. Mol Phylogenet Evol. 2002;23:447-57.

76. Sainz AC, Mauro LV, Moriyama EN, Garcia BA. Phylogeny of triatomine vectors of Trypanosoma cruzi suggested by mitochondrial DNA sequences. Genetica. 2004;121:229-40.

77. Justi SA, Dale C, Galvão C. DNA barcoding does not separate South American Triatoma (Hemiptera: Reduviidae), Chagas Disease vectors. Parasit Vectors. 2014;7:519.

78. Lent H, Wygodzinsky P. Revision of the Triatominae (Hemiptera, Reduviidae), and their significance as vectors of Chagas' Disease. Bull Amer Mus Nat Hist. 1979;163:123-520.

79. Dujardin JP, Steindel M, Chavez T, Machane M, Schofield CJ. Changes in the Sexual Dimorphism of Triatominae in the Transition from Natural to Artificial Habitats. Mem Inst Oswaldo Cruz. 1999:94(4):565-9.

80. Adams JM. Global land environments since the last interglacial. Oak Ridge National Laboratory, TN, USA. [http://www.esd.ornl.gov/ern/qen/nerc.html].

81. Adams JM, Faure H: Review and Atlas of Palaeovegetation: Preliminary land ecosystem maps of the world of the since the Last Glacial Maximum. Oak Ridge National Laboratory, TN, USA. [http://www.esd.ornl.gov/ern/qen/ adams1.html].

82. Costa J, Dornak LL, Almeida CE, Peterson AT. Distributional potential of the Triatoma brasiliensis species complex at present and under scenarios of future climate conditions. Parasites Vectors. 2014;7:238.

\section{Submit your next manuscript to BioMed Central and take full advantage of:}

- Convenient online submission

- Thorough peer review

- No space constraints or color figure charges

- Immediate publication on acceptance

- Inclusion in PubMed, CAS, Scopus and Google Scholar

- Research which is freely available for redistribution

Submit your manuscript at www.biomedcentral.com/submit 